\title{
CÓMO AFRONTAR UN PROCESO DE FISCALIZACIÓN TRIBUTARIA
}

\author{
HOW TO DEAL WITH A TAX AUDIT PROCESS
}

\author{
Adolfo Valencia GutiérRez \\ Docente Auxiliar de la Facultad de Ciencias Contables, UNMSM \\ Raúl Jesús Vergara Moncada ${ }^{* *}$ \\ Docente Auxiliar de la Facultad de Ciencias Contables, UNMSM
}

[Recepción: Febrero de 2010 / Conformidad: Abril de 2010]

\section{RESUMEN}

Los profesionales contables, como asesores y consultores en materia tributaria, tienen como prioridad que sus clientes, empresarios y contribuyentes en general, cumplan puntualmente con sus obligaciones impositivas para evitar contingencias innecesarias y antieconómicas. Por tanto es deber del profesional contable que sus clientes tengan en lo posible una situación tributaria regular, cumplan íntegramente con todas las obligaciones formales y sustanciales y que su condición fiscal no se encuadre dentro de las conductas legalmente tipificadas como infracciones o delitos tributarios, con estos antecedentes se detalla algunos aspectos generales que deberá tener en cuenta el profesional contable ante el posible hecho de afrontar un proceso de revisión fiscal cuando la Administración Tributaria así lo requiera, haciendo uso de sus facultades de fiscalización, es así como el contador público debe resaltar su función de proteger los intereses del contribuyente, haciendo respetar sus derechos y recurriendo a los diversos medios de defensa, cuando se evidencie excesos o errores, interponiendo las acciones pertinentes ante las instancias correspondientes que contempla el Derecho Constitucional Tributario.

Palabra clave: Tributación, obligaciones impositivas, contigencias tributarias, infracciones y delitos tributarios, fiscalización tributaria, derecho constitucional tributario.

\begin{abstract}
Accounting professionals, as advisers and consultants in tax, has become a priority that their clients, employers and taxpayers in general, satisfy their tax obligations promptly to avoid unnecessary and wasteful contingencies.

Therefore the duty of the accounting professional your clients have if possible a regular tax situation fully comply with all formal and substantial requirements and its fiscal condition does not fall within the conduct legally classified as infractions or tax crimes.

With this background outlined some general aspects that must take into account the professional accountant before the fact may face a fiscal review process when the tax authority so requires, using its powers of oversight, is how the accountant should highlight its role in protecting the interests of the taxpayer, enforcing their rights and resorting to various means of defense, when it became clear excesses or errors, by filing the relevant shares before the corresponding which provides the constitutional tax law
\end{abstract}

Keywords: Taxation, tax liabilities, tax contingencies, tax violations and crimes, auditing, Constitutional tax law.

\footnotetext{
* Doctorando en Ciencias de la Educación. Coordinador de la Diplomatura en Gestión Tributaria de la Unidad de Postgrado de la Facultad de Ciencias Contables, UNMSM.E-mail: avalencia@ladersam.com

** Contador Público Colegiado Certificado. Docente Auxiliar de la Facultad de Ciencias Contables, UNMSM. E-mail: rvergara64@yahoo.es
} 


\section{INTRODUCCIÓN}

Los profesionales contables, como asesores y consultores en materia tributaria, tienen como prioridad que sus clientes, empresarios y contribuyentes en general, cumplan puntualmente con sus obligaciones impositivas para evitar contingencias innecesarias y antieconómicas.

Por tanto es deber del profesional contable que sus clientes tengan en lo posible una situación tributaria regular, cumplan íntegramente con todas las obligaciones impositivas y que su condición fiscal no se encuadre dentro de las conductas legalmente tipificadas como infracciones o delitos tributarios.

\section{ANTECEDENTES}

Con estos antecedentes en este artículo, se detalla algunos aspectos generales que debería tener en cuenta el profesional contable al afrontar un proceso de revisión fiscal por parte de la Administración Tributaria, que en el ejercicio de sus facultades de fiscalización, podría lesionar los derechos de los contribuyentes con interpretaciones erróneas de la documentación contable o cometer excesos en su actuación.

Es así, como el contador debe resaltar su función de proteger los intereses del contribuyente, haciendo respetar sus derechos y recurriendo a los diversos medios de defensa, cuando se evidencie excesos o errores, interponiendo las acciones pertinentes ante las instancias correspondientes, que contempla el Código Tributario.

\section{ASPECTOS GENERALES}

\section{La Carta de Presentación}

En la marcha normal de las operaciones mercantiles de los contribuyentes, uno de los re- tos más importantes que tiene que afrontar es la notificación en el domicilio fiscal o procesal fijado por el contribuyente, mediante carta de presentación del requerimiento correspondiente, con el fin de verificar el correcto cumplimiento de las normas tributarias a través de programas de fiscalización propios de la Administración Tributaria, donde se presenta a los auditores a cargo de la verificación.

\section{Artículo $11^{\circ}$. Domicilio fiscal y procesal}

El domicilio fiscal es el lugar fijado dentro del territorio nacional para todo efecto tributario; sin perjuicio de la facultad del deudor tributario de señalar expresamente un domicilio procesal al iniciar cada uno de sus procedimientos tributarios. El domicilio procesal deberá estar ubicado dentro del radio urbano que señale la Administración Tributaria.

Los deudores tributarios tienen la obligación de fijar y cambiar su domicilio fiscal, conforme lo establezca la Administración Tributaria.

El domicilio fiscal fijado por el deudor tributario se considera subsistente mientras su cambio no sea comunicado a la Administración Tributaria en la forma establecida por ésta. En aquellos casos en que la Administración Tributaria haya notificado al deudor tributario a efecto de realizar una verificación, fiscalización o haya iniciado el Procedimiento de Cobranza Coactiva, éste no podrá efectuar el cambio de domicilio fiscal hasta que ésta concluya, salvo que a juicio de Administración exista causa justificada para el cambio.

La Administración Tributaria está facultada a requerir a los deudores tributarios que fijen un nuevo domicilio fiscal cuando, a su criterio, éste dificulte el ejercicio de sus funciones. 
Excepcionalmente, en los casos que se establezca mediante Resolución de Superintendencia, la Administración Tributaria podrá considerar como domicilio fiscal los lugares señalados en el párrafo siguiente, previo requerimiento al deudor tributario.

En caso que el deudor tributario no cumpla con efectuar el cambio requerido en el plazo otorgado por la Administración, se podrá considerar como domicilio fiscal cualesquiera de los lugares a que se hace mención en los Artículos $12^{\circ}, 13^{\circ}, 14^{\circ}$ y $15^{\circ}$, según el caso. Dicho domicilio no podrá ser variado por el deudor tributario sin autorización de la Administración.

La Administración Tributaria no podrá requerir el cambio de domicilio fiscal, cuando éste sea:

a) La residencia habitual, tratándose de personas naturales.

b) El lugar donde se encuentra la dirección o administración efectiva del negocio, tratándose de personas jurídicas.

c) El de su establecimiento permanente en el país, tratándose de las personas domiciliadas en el extranjero.

Cuando no sea posible notificar al deudor tributario en el domicilio procesal fijado por éste, la Administración realizará las notificaciones que correspondan en su domicilio fiscal.

Consecuencias y alcances. Con esta carta de presentación la Administración Tributaria pone en conocimiento del contribuyente el uso de su facultad de fiscalización para controlar el cumplimiento de las obligaciones impositivas, es decir verificar o comprobar que los hechos imponibles declarados por los contribuyentes correspondan a las operaciones reales que ha realizado en los diferentes períodos tributarios no prescritos, utilizando una serie de acciones para examinar los hechos económicos, con la finalidad de determinar la prestación tributaria.

\section{Artículo $62^{\circ}$. Facultad de fiscalización}

La facultad de fiscalización de la Administración Tributaria se ejerce en forma discrecional, de acuerdo a lo establecido en el último párrafo de la Norma IV del Título Preliminar. (1)

El ejercicio de la función fiscalizadora incluye la inspección, investigación y el control del cumplimiento de obligaciones tributarias, incluso de aquellos sujetos que gocen de inafectación, exoneración o beneficios tributarios. Para tal efecto, dispone de las siguientes facultades discrecionales:

1. Exigir a los deudores tributarios la exhibición de sus libros y registros contables y documentación sustentatoria, los mismos que deberán ser llevados de acuerdo con las normas correspondientes. Sólo en el caso que, por razones debidamente justificadas, el deudor tributario requiera un término para dicha exhibición, la Administración deberá otorgarle un plazo no menor de dos días hábiles.

También podrá exigir la presentación de informes y análisis relacionados con hechos imponibles, exhibición de documentos y correspondencia comercial relacionada con hechos que determinen tributación, en la forma y condiciones solicitadas, para lo cual la Administración deberá otorgar un plazo que no podrá ser menor de tres días hábiles

2. En los casos que los deudores tributarios o terceros registren sus operaciones contables mediante sistemas de procesamiento electrónico de datos o sistemas de microarchivos, la Administración Tributaria podrá exigir:

a) Copia de la totalidad o parte de los soportes portadores de microformas gravadas o de los soportes magnéticos utilizados en sus aplicaciones que in-

Vol. 17(33) 2010 | QVIPURAMAYOC / 135 
cluyan datos vinculados con la materia imponible, debiendo suministrar a la Administración los instrumentos materiales a este efecto, los que les serán restituidos a la conclusión de la fiscalización o verificación.

b) Información o documentación relacionada con el equipamiento informático incluyendo programas fuente, diseño y programación utilizados $y$ de las aplicaciones implantadas, ya sea que el procesamiento se desarrolle en equipos propios o alquilados o, que el servicio sea prestado por un tercero.

c) El uso de equipo técnico de recuperación visual de microformas y de equipamiento de computación para la realización de tareas de auditoría tributaria, cuando se hallaren bajo fiscalización o verificación.

La Administración podrá establecer las características que deberán reunir los registros de información básica almacenable en los archivos magnéticos. Asimismo, señalará los datos que obligatoriamente deberán registrarse, la información inicial por parte de los deudores tributarios y terceros, así como la forma y plazos en que deberán cumplirse las obligaciones dispuestas en este numeral.

3. Requerir a terceros informaciones y exhibición de sus libros, registros, documentos, emisión y uso de tarjetas de crédito o afines y correspondencia comercial relacionada con hechos que determinen tributación, en la forma y condiciones solicitadas, para lo cual la Administración deberá otorgar un plazo que no podrá ser menor de tres días hábiles.

4. Solicitar la comparecencia de los deudores tributarios o terceros para que pro- porcionen la información que se estime necesaria, otorgando un plazo no menor de cinco días hábiles, más el término de la distancia de ser el caso. Las manifestaciones obtenidas en virtud de la citada facultad deberán ser valoradas por los órganos competentes en los procedimientos tributarios. (2)

5. Efectuar tomas de inventario de existencias y activos fijos o controlar la ejecución, efectuar la comprobación física, su valuación y registro; así como practicar arqueos de caja, valores y documentos de control de ingresos.

Las actuaciones indicadas serán ejecutadas en forma inmediata con ocasión de la intervención.

6. Cuando la Administración presuma la existencia de evasión tributaria, podrá inmovilizar los libros, archivos, documentos, registros en general y bienes, de cualquier naturaleza, por un período no mayor de cinco días hábiles, prorrogables por otro igual. (3)

Aduanas - ADUANAS, el plazo de inmovilización será de diez (10) días hábiles, prorrogables por un plazo igual. La Administración Tributaria dispondrá lo necesario para la custodia de aquello que haya sido inmovilizado.

7. Cuando la Administración presuma la existencia de evasión tributaria, podrá practicar incautaciones de libros, archivos, documentos, registros en general y bienes, de cualquier naturaleza, que guarden relación con la realización de hechos imponibles, por un plazo que no podrá exceder de quince (15) días hábiles. (4)

La Administración Tributaria procederá a la incautación previa autorización judicial. Para tal efecto, la solicitud de la Administración será motivada y deberá ser 
resuelta por cualquier juez Especializado en lo Penal, en el término de veinticuatro (24) horas, sin correr traslado a la otra parte. (5)

8. Practicar inspecciones en los locales ocupados, bajo cualquier título, por los deudores tributarios, así como en los medios de transporte.

Para realizar las inspecciones cuando los locales estuvieren cerrados o cuando se trate de domicilios particulares, será necesario solicitar autorización judicial, la que debe ser resuelta en forma inmediata y otorgándose el plazo necesario para su cumplimiento.

9. Requerir el auxilio de la fuerza pública para el desempeño de sus funciones, que será prestado de inmediato bajo responsabilidad.

10. Solicitar información sobre los deudores tributarios sujetos a fiscalización a las entidades del sistema bancario y financiero sobre:

a) Operaciones pasivas con sus clientes, las mismas que deberán ser requeridas por el Juez a solicitud de la Administración Tributaria, siempre que se trate de información de carácter específica e individualizada. La solicitud deberá ser motivada y resuelta en el término de setenta y dos (72) horas, bajo responsabilidad. (6)

b) Las demás operaciones con sus clientes, las mismas que deberán ser proporcionadas en la forma, plazo y condiciones que señale la Administración Tributaria.

11. Investigar los hechos que configuran infracciones tributarias, asegurando los medios de prueba e identificando al infractor.

12. Requerir a las entidades públicas o privadas para que informen o comprueben el cumplimiento de obligaciones tributarias de los sujetos con los cuales realizan operaciones, bajo responsabilidad.

13. Solicitar a terceros informaciones técnicas o peritajes.

14. Dictar las medidas para erradicar la evasión tributaria.

15. Evaluar las solicitudes presentadas y otorgar, en su caso, las autorizaciones respectivas en función a los antecedentes $y / o$ al comportamiento tributario del contribuyente.

16. Tratándose de la Superintendencia Nacional de Administración Tributaria - SUNAT, autorizar los libros de actas, así como los registros y libros contables vinculados con asuntos tributarios, que el contribuyente deba llevar de acuerdo a ley.

El procedimiento para la autorización será establecido por la SUNAT mediante Resolución de Superintendencia. A tal efecto, podrá delegarse en terceros la legalización de los libros y registros antes mencionados.

Para conceder los plazos establecidos en este artículo, la Administración tendrá en cuenta la oportunidad en que solicita la información o exhibición, y las características de las mismas.

Ninguna persona o entidad, pública o privada, puede negarse a suministrar a la Administración Tributaria la información que ésta solicite para determinar la situación económica o financiera de los deudores tributarios.

Formulario de requerimiento. El Requerimiento es un Formulario numerado de la Administración Tributaria donde se enumera y detalla la información y/o documentación requerida, así como del período o períodos a revisar y de la fecha y hora de presentación al auditor(es) designados. 


\section{El proceso de fiscalización}

La Administración Tributaria, luego de la notificación del requerimiento de información y/o documentación pertinente inicia el proceso de fiscalización con el objetivo de revisar el cumplimiento de las obligaciones tributarias.

Inicio de la Fiscalización. El inicio de la fiscalización se efectúa con la entrega del contribuyente de toda la documentación requerida, principalmente:

- Comprobantes de Pago de Ventas.

- Comprobantes de Pago de Compras.

- Notas de Contabilidad.

- Declaración y Liquidación de Importación.

- Registro de Compras y Ventas.

- Libros de Inventarios y Balances, Mayor, Diario y Caja, según corresponda.

- Declaraciones de Pago de IGV-RENTA del período requerido.

- Declaración de Autorización de Impresión de Comprobantes de Pago.

Pasando el Auditor a realizar lo siguiente:

1. Examen de los Registros de Contabilidad.

- Revisará la situación legal de los libros contables.

- Que se encuentren legalizados.

- Que sean llevados de acuerdo a las normas.

- Que los registros contables estén al día.

2. Exámenes de las declaraciones juradas de IGV-RENTA y Declaraciones Juradas Anuales y otras comunicaciones de ley.

- Que la presentación de las declaraciones se haya realizado dentro de los plazos establecidos.

- Que los pagos hayan sido efectuado en los formularios y oficinas autorizadas por la SUNAT.
- Confrontará que la información que tiene la Administración Tributaria coincida con la que proporcione el contribuyente.

- Que lo pagado corresponda a lo declarado.

- Que la numeración de los comprobantes de pago en uso se encuentre declarada y dentro del plazo de ley.

- Verificará el débito y crédito fiscal, efectuando los cruces de lo registrado con lo declarado.

- Efectuará cruces de la base imponible registrada y la declarada.

Segundo requerimiento. El Auditor emitirá un segundo requerimiento en los siguientes casos:

- No exhibición de la información y/o documentación contable.

- No presentación de las declaraciones que contengan la determinación de la deuda tributaria.

Requerimientos adicionales. El auditor en el proceso de fiscalización emitirá requerimientos adicionales en los siguientes casos:

- Cuando necesita información específica de algún punto de información y/o documentación que permita esclarecer los hechos imponibles.

- Dar plazo al contribuyente para que cumpla con regularizar las infracciones detectadas.

- Para que el contribuyente sustente los reparos u observaciones detectadas.

Cierre de Requerimientos. Terminada la verificación el auditor procede a llenar el Resultado del Requerimiento donde consignará en forma clara y precisa lo siguiente:

- Si cumplió con presentar toda la documentación requerida.

- $\quad$ Si se encontraron reparos u observaciones.

- Si se encontraron infracciones cometidas. 


\section{La determinación de la obligación tributaria}

La determinación tributaria es la fijación de la obligación impositiva del contribuyente, que es llevada a cabo tanto por el deudor como por la Administración Tributaria, es decir este proceso permite a la Administración Tributaria o al contribuyente, definir específicamente los montos imponibles y el importe a tributar.

\section{Artículo 590. Determinación de la obligacion tributaria}

Por el acto de la determinación de la obligación tributaria:

a) El deudor tributario verifica la realización del hecho generador de la obligación tributaria, señala la base imponible y la cuantía del tributo.

b) La Administración Tributaria verifica la realización del hecho generador de la obligación tributaria, identifica al deudor tributario, señala la base imponible y la cuantía del tributo.

Determinación de observaciones y reparos. Luego de terminado el proceso de fiscalización y si existen controversias, el Auditor procede a notificar la Resolución de Determinación u Orden de Pago, donde se detallan los reparos tributarios (observaciones) que adolecen las declaraciones tributarias del período revisado.

Rectificatorias. En el proceso de fiscalización, el Auditor al observar reparos a las declaraciones tributarias, induce al contribuyente a la presentación de las declaraciones rectificatorias correspondientes, que sustituyen a las presentadas originalmente con nuevas bases imponibles.

Consecuencias. Una de las facultades de la Administración Tributaria es la de aplicar sanciones a los infractores tributarios, es decir tiene la facultad discrecional que le permite aplicar sanciones con cierta gradualidad, tomando en consideración la naturaleza y la cuantía de la infracción.

También tiene la facultad de denunciar el delito de defraudación tributaria, al descubrir conductas intencionales que suponen el uso de "artificios" (fraude) para dejar de pagar los tributos.

\section{El procedimiento tributario}

En su relación con el contribuyente, la Administración Tributaria emite documentos donde se comunican las deudas, sanciones aplicadas o resultados de las acciones efectuadas por la Administración Tributaria, estos documentos son:

- Valores, cuando el documento da a conocer al contribuyente o representado legal el monto de su deuda tributaria.

- Resoluciones Administrativas, cuando la Administración Tributaria da a conocer al deudor o representante legal, la aplicación de alguna sanción no pecuniaria o el resultado de algún procedimiento tributario.

\section{Artículo $103^{\circ}$. Actos de la administración tributaria $(7)$}

Los actos de la Administración Tributaria serán motivados y constarán en los respectivos instrumentos o documentos. La notificación de los mismos se considera válida cuando se realice en el domicilio fiscal del deudor tributario, mientras éste no haya comunicado el cambio de domicilio, salvo lo dispuesto en el Artículo 104․

Orden de Pago. La orden de pago es el acto que contiene una exigencia de cancelación de la deuda tributaria, desde el día siguiente de su notificación. 


\section{Artículo $7^{\circ}$. Orden de pago}

La Orden de Pago es el acto en virtud del cual la Administración exige al deudor tributario la cancelación de la deuda tributaria, sin necesidad de emitirse previamente la Resolución de Determinación, en los casos siguiente:

1. Por tributos autoliquidados por el deudor tributario.

2. Por anticipos o pagos a cuenta, exigidos de acuerdo a ley.

3. Por tributos derivados de errores materiales de redacción o de cálculo en las declaraciones, comunicaciones o documentos de pago.

Para determinar el monto de la Orden de Pago, la Administración considerará la base imponible.

4. Tratándose de deudores tributarios que no declararon ni determinaron su obligación o que habiendo declarado no efectuaron la determinación de la misma, por uno o más períodos tributarios, previo requerimiento para que realicen la declaración y determinación omitidas y abonen los tributos correspondientes, dentro de un término de tres días hábiles, de acuerdo al procedimiento establecido en el artículo siguiente, sin perjuicio que la Administración Tributaria pueda optar por practicarles una determinación de oficio.

5. Cuando la Administración Tributaria realice una verificación de los libros y registros contables del deudor tributario y encuentre tributos no pagados.

Las Órdenes de Pago que emita la Administración, en lo pertinente, tendrán los mismos requisitos formales que la Resolución de Determinación, a excepción de los motivos determinantes del reparo u observación.

La resolución de determinación. La Resolución de Determinación tiene la natu- raleza, sin embargo por propia definición, no es en principio una exigencia de pago, sino el acto por el cual solamente se pone en conocimiento del contribuyente, la existencia de la deuda tributaria y solo es exigible sin se efectúa el reclamo dentro del plazo de ley.

\section{Artículo $76^{\circ}$. Resolución de determinación}

La Resolución de Determinación es el acto por el cual la Administración Tributaria pone en conocimiento del deudor tributario el resultado de su labor destinada a controlar el cumplimiento de las obligaciones tributarias, y establece la existencia del crédito o de la deuda tributaria.

\section{Artículo $77^{\circ}$. Requisitos de resoluciones de determinación y de multa}

La Resolución de Determinación será formulada por escrito y expresará:

1. El deudor tributario.

2. El tributo y el período al que corresponda.

3. La base imponible.

4. La tasa.

5. La cuantía del tributo y sus intereses.

6. Los motivos determinantes del reparo $\mathrm{u}$ observación, cuando se rectifique la declaración tributaria.

7. Los fundamentos y disposiciones que la amparen.

Tratándose de Resoluciones de Multa contendrán necesariamente los requisitos establecidos en los numerales 1 y 7 , así como referencia a la infracción, el monto de la multa y los intereses.

La Administración Tributaria podrá emitir en un sólo documento las Resoluciones de Determinación y de Multa, las cuales podrán impugnarse conjuntamente, siempre que la infracción esté referida a un mismo deudor tributario, tributo y período. 
Resoluciones fictas. Son las resoluciones emitidas por la Administración Tributaria, en el caso de infracciones tributarias sancionadas con el cierre temporal de establecimiento $\mathrm{u}$ oficinas de profesionales independientes, con el comiso de bienes y la resolución de internamiento temporal del vehículo. Estas resoluciones deben ser debidamente motivadas o justificadas.

Cobranza coactiva. La Administración Tributaria, ejerce la facultad de realizar actos coercitivos destinados a lograr el cobro de la deuda tributaria exigible, por intermedio del ejecutor coactivo mediante el apercibimiento para que el deudor cumpla con el mandato.

\section{Artículo $115^{\circ}$. Deuda exigible en cobran- za coactiva (8)}

La deuda exigible dará lugar a las acciones de coerción para su cobranza.

A este fin se considera deuda exigible:

a) La establecida mediante Resolución de Determinación o de Multa notificadas por la Administración y no reclamadas en el plazo de ley.

b) La establecida por Resolución no apelada en el plazo de ley, o por Resolución del Tribunal Fiscal.

c) La constituida por la amortización e intereses de la deuda materia de aplazamiento o fraccionamiento pendientes de pago, cuando se incumplen las condiciones bajo las cuales se otorgó ese beneficio.

d) La que conste en Orden de Pago notificada conforme a ley.

e) Las costas y los gastos en que la Administración hubiera incurrido, tanto en el procedimiento de cobranza coactiva, como en la aplicación de sanciones no pecuniarias de conformidad con las normas vigentes. (9)

Para el cobro de las costas se requiere que éstas se encuentren fijadas en el Arancel de
Costas del Procedimiento de Cobranza Coactiva que se apruebe mediante resolución de Administración Tributaria; mientras que para el cobro de los gastos se requiere que éstos se encuentren sustentados con la documentación correspondiente.

Cualquier pago indebido o en exceso de ambos conceptos será devuelto por la Administración Tributaria. (10)

\section{MEDIO DE DEFENSA DEL CONTRIBUYENTE}

El contribuyente en caso de controversia de los actos de la Administración Tributaria, de acuerdo a ley tiene la potestad de interponer acciones ante las instancias respectivas, cuando los actos o resoluciones dictadas por ella, le provocan un perjuicio, ya sea por aplicación indebida de las normas tributarias, la no aplicación o por excesos del auditor de turno.

En tal sentido el trámite del procedimiento contencioso - tributario, tipificado en el Art. 124 del Código Tributario indica: Son etapas del Procedimiento Contencioso - Tributario:

a) La reclamación ante la Administración Tributaria.

b) La apelación ante el Tribunal Fiscal.

Reclamación. El contribuyente afectado por un acto de la Administración Tributaria, al expresar disconformidad, controversia u oposición, interpone el recurso de reclamación mediante solicitud ante la primera instancia que en este caso es la SUNAT respeto a los tributos que administra, se presenta dentro del término de VEINTE DIAS HABILES improrrogables computados desde el día hábil siguiente de la notificación del acto o resolución.

Son actos susceptibles de ser reclamados por el deudor, mediante escrito fundamentado y autorizado por un letrado, donde la defensa fuera cautiva, adjuntando los requisitos correspondientes, los siguientes: 
- La Resolución de Determinación.

- La Resolución de Multa.
- La Orden de Pago.

- La Resolución Ficta.

La reclamación ante la SUNAT

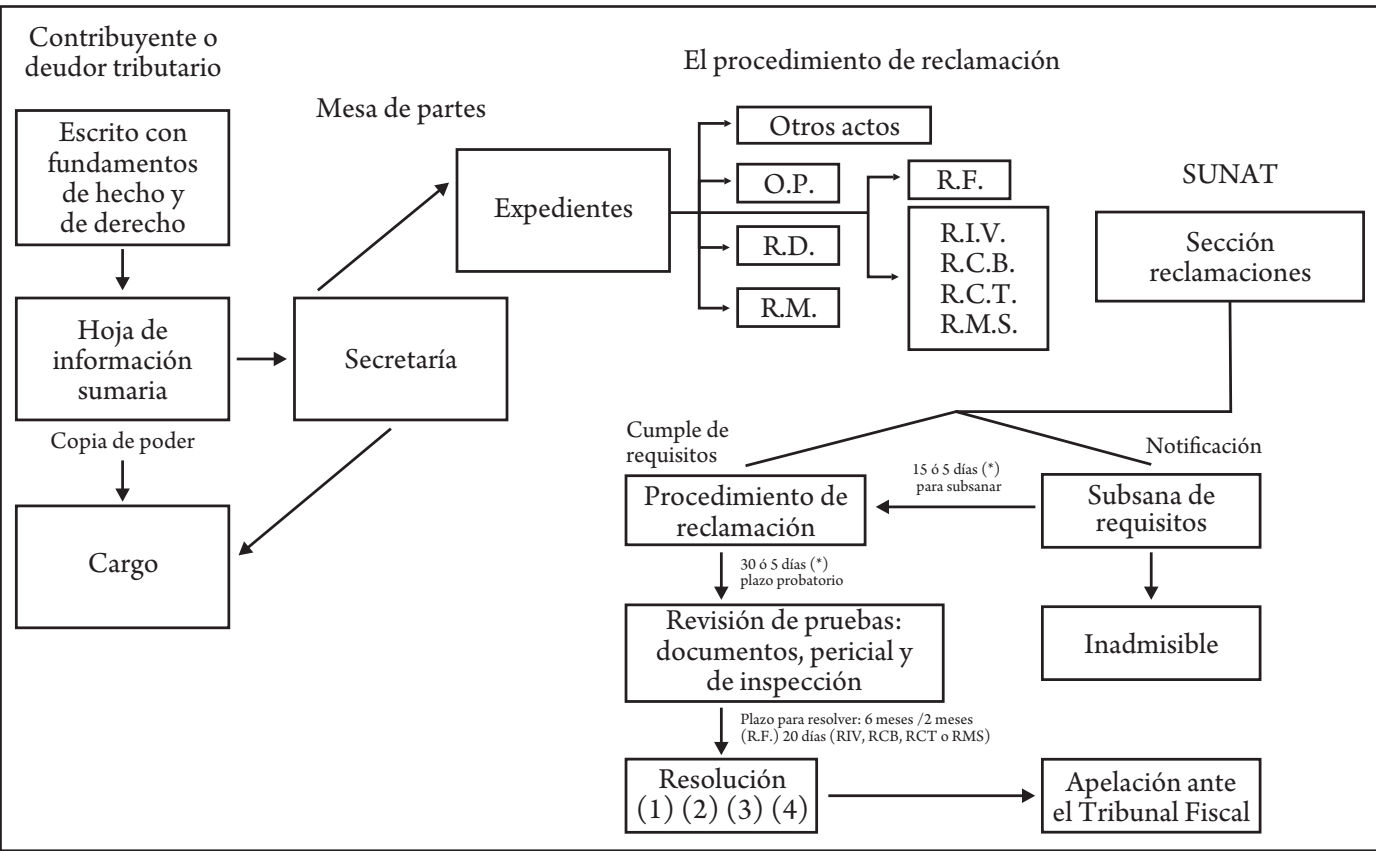

\section{Artículo $1^{\circ} 5^{\circ}$. Actos reclamables}

Puede ser objeto de reclamación la Resolución de Determinación, la Orden de Pago y la Resolución de Multa.

También son reclamables la resolución ficta sobre recursos no contenciosos, las resoluciones que establezcan sanciones de comiso de bienes, internamiento temporal de vehículos y cierre temporal de establecimiento $\mathrm{u}$ oficina de profesionales independientes, así como las resoluciones que sustituyan a esta última y al comiso, y los actos que tengan relación directa con la determinación de la deuda tributaria. (11)

\section{Artículo $136^{\circ}$. Requisito del pago previo para interponer reclamaciones}

Tratándose de Resoluciones de Determinación y de Multa, para interponer recla- mación no es requisito el pago previo de la deuda tributaria por la parte que constituye motivo de la reclamación; pero para que ésta sea aceptada, el reclamante deberá acreditar que ha abonado la parte de la deuda no reclamada actualizada hasta la fecha en que realice el pago.

Para interponer reclamación contra la Orden de Pago es requisito acreditar el pago previo de la totalidad de la deuda tributaria actualizada hasta la fecha en que realice el pago, excepto en los casos establecidos en el segundo y tercer párrafo del Artículo 119o.

\section{Artículo $137^{\circ}$. Requisitos de admisibili- dad (12)}

La reclamación se iniciará mediante escrito fundamentado, autorizado por letrado en los lugares donde la defensa fuera cautiva, adjuntando la Hoja de Información Sumaria 
correspondiente, cuyo formato se aprobará mediante Resolución de Superintendencia o norma de rango similar. Tratándose de reclamaciones contra Resolución de Determinación y Resolución de Multa, éstas se presentarán en el término improrrogable de veinte (20) días hábiles computados desde el día hábil siguiente a aquel en que se notificó el acto o resolución recurrida.

Cuando las Resoluciones de Determinación y de Multa se reclamen vencido el mencionado término, deberá acreditarse el pago de la totalidad de la deuda tributaria que se reclama, actualizada hasta la fecha de pago, o presentar carta fianza bancaria o financiera por el monto de la deuda actualizada hasta por seis meses posteriores a la fecha de la interposición de la reclamación, con una vigencia de seis meses, debiendo renovarse por períodos similares dentro del plazo que señale la Administración. En caso de que la Administración declare improcedente o procedente en parte la reclamación y el deudor tributario apele dicha resolución, éste deberá mantener la vigencia de la carta fianza durante la etapa de la apelación por el mismo monto, plazos y períodos señalados precedentemente. La carta fianza será ejecutada si el Tribunal Fiscal confirma o revoca en parte la resolución apelada, o si ésta no hubiese sido renovada de acuerdo a las condiciones señaladas por la Administración Tributaria. Si existiera algún saldo a favor del deudor tributario, como consecuencia de la ejecución de la carta fianza, será devuelto de oficio. (13)

Las condiciones de la carta fianza, así como el procedimiento para su presentación serán establecidas por la Administración Tributaria mediante Resolución de Superintendencia o norma de rango similar.

Tratándose de las resoluciones que establezcan sanciones de comiso de bienes, internamiento temporal de vehículos y cie- rre temporal de establecimiento u oficina de profesionales independientes, así como las resoluciones que sustituyan a esta última y al comiso, la reclamación se presentará en el plazo de cinco días hábiles computados desde el día hábil siguiente a aquel en que se notificó la resolución recurrida.

Apelación. El recurso de apelación es el acto procesal cuyo objetivo es lograr que un tribunal jerárquicamente superior a aquel cuya resolución se apela, revoque o modifique una resolución que se considera errónea, se presenta dentro de los QUINCE DIAS HABILES de la notificación certificada, adjuntando escrito fundamentado y firma del letrado correspondiente ante la instancia de la Administración Tributaria, quien elevará el presente recurso ante el TRIBUNAL FISCAL luego de aceptada su admisión con los requisitos correspondientes.

Son actos apelables:

- La resolución de reclamación expresa o ficta expedida en primera instancia.

- La resolución que resuelve la solicitud no contenciosa vinculada a la determinación de la obligación tributaria.

- La Resolución de Determinación o de Multa u Orden de Pago cuando la impugnación sea de puro derecho, es decir en las que sólo se discute el régimen legal, no existiendo por tanto hechos que probar.

- Las resoluciones que establezcan cierre temporal de establecimiento o comiso de bienes.

- Las resoluciones del ejecutor coactivo que traten de tercerías, en caso de embargos.

Es competente y está facultado para resolver en última instancia administrativa, el TRIBUNAL FISCAL, en las reclamaciones sobre materia tributaria general, regional y local. 
Artículo $145^{\circ}$. Presentación de la apelación (14)

El recurso de apelación deberá ser presentado ante el órgano que dictó la resolución apelada el cual, sólo en el caso que se cumpla con los requisitos de admisibilidad establecidos para este recurso, elevará el expediente al Tribunal Fiscal dentro de los treinta (30) días hábiles siguientes a la presentación de la apelación. Tratándose de la apelación de resoluciones que resuelvan los reclamos sobre sanciones de comiso de bienes, internamiento temporal de vehículos y cierre temporal de establecimiento $\mathrm{u}$ otra oficina de profesionales independientes, así como las resoluciones que sustituyan a esta última y al comiso, se elevará el expediente al Tribunal Fiscal dentro de los quince (15) días hábiles siguientes a la presentación de la apelación.

\section{Artículo $146^{\circ}$. Requisitos de la apelación (15)}

La apelación de la resolución ante el Tribunal Fiscal deberá formularse dentro de los quince (15) días hábiles siguientes a aquel en que se efectuó su notificación certificada, adjuntando escrito fundamentado con firma de letrado en los lugares donde la defensa fuera cautiva y la Hoja de Información Sumaria, cuyo formato se aprobará mediante Resolución de Superintendencia o norma de rango similar.

La Administración Tributaria notificará al apelante para que dentro del término de quince (15) días hábiles subsane las omisiones que pudieran existir cuando el recurso de apelación no cumpla con los requisitos para su admisión o trámite. Asimismo, tratándose de apelaciones contra la resolución que resuelve la reclamación de resoluciones que establezcan sanciones de comiso de bienes, internamiento temporal de vehículos y cierre temporal de establecimiento u oficina de profesionales independientes, así como las resoluciones que sustituyan a esta última y al comiso, la Administración Tributaria notificará al apelante para que dentro del término de cinco días hábiles subsane dichas omisiones.

Vencidos dichos términos sin la subsanación correspondiente, se declarará inadmisible la apelación.

Para interponer la apelación no es requisito el pago previo de la deuda tributaria por la parte que constituye el motivo de la apelación, pero para que ésta sea aceptada, el apelante deberá acreditar que ha abonado la parte no apelada actualizada hasta la fecha en que se realice el pago.

La apelación será admitida vencido el plazo señalado en el primer párrafo, siempre que se acredite el pago de la totalidad de la deuda tributaria apelada actualizada hasta la fecha de pago o se presente carta fianza bancaria o financiera por el monto de la deuda actualizada hasta por seis meses posteriores a la fecha de la interposición de la apelación, y se formule dentro del término de seis meses contados a partir del día siguiente a aquel en que se efectuó la notificación certificada.

La referida carta fianza debe otorgarse por un período de seis meses y renovarse por períodos similares dentro del plazo que señale la Administración. La carta fianza será ejecutada si el Tribunal Fiscal confirma o revoca en parte la resolución apelada o si ésta no hubiese sido renovada de acuerdo a las condiciones señaladas por la Administración Tributaria.

Las condiciones de la carta fianza, así como el procedimiento para su presentación serán establecidas por la Administración Tributaria mediante Resolución de Superintendencia o norma de rango similar. 
Artículo $150^{\circ}$. Plazo para resolver la apelación

El Tribunal Fiscal resolverá las apelaciones dentro del plazo de doce meses contados a partir de la fecha de ingreso de los actuados al Tribunal.

La Administración Tributaria o el apelante podrán solicitar el uso de la palabra dentro de los cuarenta y cinco (45) días hábiles de interpuesto el recurso de apelación, debiendo el Tribunal Fiscal señalar una misma fecha y hora para el informe de ambas partes.

El Tribunal Fiscal no podrá pronunciarse sobre aspectos que, considerados en la reclamación, no hubieran sido examinados y resueltos en primea instancia; en tal caso declarará la insubsistencia de la resolución, reponiendo el proceso al estado que corresponda.

Procedimiento contencioso tributario

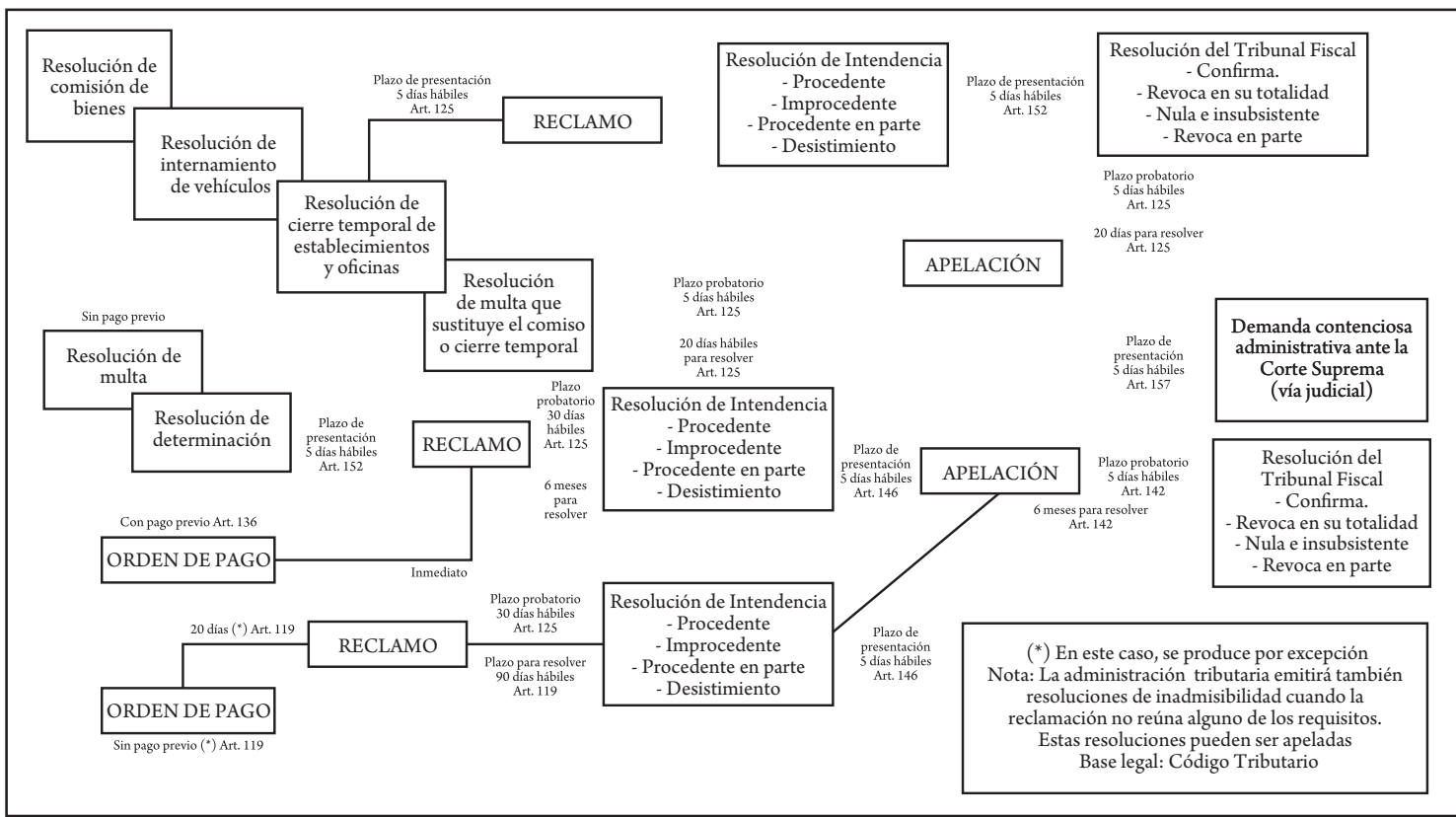

Artículo $152^{\circ}$. Apelación contra resolución que resuelve las reclamaciones de cierre, comiso o internamiento (16)

Las resoluciones que resuelvan las reclamaciones contra aquellas que establezcan sanciones de internamiento temporal de vehículos, comiso de bienes y cierre temporal de establecimiento $\mathrm{u}$ oficina de profesionales independientes, las resoluciones que sustituyan a esta última y al comiso, podrán ser apeladas ante el Tribunal Fiscal dentro de los cinco días hábiles siguientes a los de su notificación.
El recurso de apelación deberá ser presentado ante el órgano recurrido quien dará la alzada luego de verificar que se ha cumplido con el plazo establecido en el párrafo anterior.

El apelante deberá ofrecer y actuar las pruebas que juzgue conveniente, dentro de los cinco días hábiles siguientes a la fecha de interposición del recurso.

El Tribunal Fiscal deberá resolver la apelación dentro del plazo de veinte (20) días hábiles contados a partir del día siguiente de la recepción del expediente remitido por la Administración Tributaria. La resolución 
del Tribunal Fiscal puede ser impugnada mediante demanda contencioso-administrativa ante el Poder Judicial.

Queja. El Código Tributario establece que los deudores tributarios podrán interponer recurso de queja contra las actuaciones o procedimientos que los afecten directamente o infrinjan lo establecido por él mismo.

Es competente para conocer este recurso el TRIBUNAL FISCAL y deberá resolver dentro del término de VEINTE DÍAS HÁBILES de presentada la queja.

\section{Artículo $155^{\circ}$. Recurso de queja}

El recurso de queja se presenta cuando exis$\tan$ actuaciones o procedimientos que afecten directamente o infrinjan lo establecido en este Código; debiendo ser resuelto por:

a) El Tribunal Fiscal dentro del plazo de veinte (20) días hábiles de presentado el recurso, tratándose de recursos contra la Administración Tributaria.

b) El Ministerio de Economía y Finanzas dentro del plazo de veinte (20) días, tratándose de recursos contra el Tribunal Fiscal.

\section{Artículo $157^{\circ}$. Demanda contencioso - administrativa}

La resolución del Tribunal Fiscal agota la vía administrativa. Dicha resolución podrá impugnarse mediante el Proceso Contencioso Administrativo, el cual se regirá por las normas contenidas en el presente Código y, supletoriamente, por la Ley No. 27584, Ley que regula el Proceso Contencioso Administrativo.

La demanda podrá ser presentada por el deudor tributario ante la Sala contencioso Administrativa de la Corte Superior respectiva, dentro del término de tres (3) me- ses computados a partir del día siguiente de efectuada la notificación de la resolución debiendo contener peticiones concretas. La presentación de la demanda no interrumpe la ejecución de los actos o resoluciones de la Administración Tributaria.

\section{Artículo $158^{\circ}$. Requisitos de admisibilidad - deudor tributario (17)}

Para la admisión de a demanda contenciosoadministrativa, será indispensable que ésta sea presentada dentro del plazo señalado en el artículo anterior. El órgano jurisdiccional, al admitir a trámite la demanda, requerirá al Tribunal Fiscal o a la Administración Tributaria, de ser el caso, para que le remita el expediente administrativo en un plazo de treinta (30) días hábiles de notificado.

\section{CONCLUSIÓN}

Es deber del profesional contable que sus clientes tengan en lo posible una situación tributaria regular, cumplan íntegramente con todas las obligaciones impositivas y que su condición fiscal no se encuadre dentro de las conductas legalmente tipificadas como infracciones o delitos tributarios.

El contador debe resaltar su función de proteger los intereses del contribuyente, haciendo respetar sus derechos y recurriendo a los diversos medios de defensa, cuando se evidencie excesos o errores, interponiendo las acciones pertinentes ante las instancias correspondientes, que contempla el Código Tributario.

Las Órdenes de Pago que emita la Administración, en lo pertinente, tendrán los mismos requisitos formales que la Resolución de Determinación, a excepción de los motivos determinantes del reparo u observación. 


\section{REFERENCIAS BIBLIOGRÁFICAS}

1. Párrafo sustituido por el artículo $8^{\circ}$ de la Ley $\mathrm{N}^{\circ} 27335$, publicada el 31 de julio de 2000.

2. Numeral sustituido por el artículo $9^{\circ} \mathrm{de}$ la Ley No 27335, publicada el 31 de julio de 2000.

3. Párrafo sustituido por el artículo $17^{\circ} \mathrm{de}$ la Ley No 27038, publicada el 31 de diciembre de 1998.

4. Párrafo sustituido por el artículo $17^{\circ}$ de la Ley No 27038, publicada el 31 de diciembre de 1998.

5. Párrafo modificado por el artículo $3^{\circ}$ de la Ley No 26663, publicada el 22 de setiembre de 1996.

6. Inciso sustituido por el artículo $17^{\circ}$ de la Ley No 27038, publicada el 31 de diciembre de 1998.

7. Artículo sustituido por el artículo $28^{\circ}$ de la Ley No 27038, publicada el 31 de diciembre de 1998.

8. Artículo sustituido por el artículo $31^{\circ} \mathrm{de}$ la Ley No 27038, publicada el 31 de diciembre de 1998.
9. Inciso sustituido por el artículo $11^{\circ}$ de la Ley No 27335, publicada el 31 de julio de 2000.

10. Párrafo sustituido por el artículo $11^{\circ}$ de la Ley No 27335, publicada el 31 de julio de 2000.

11. Párrafo sustituido por el artículo $35^{\circ}$ de la Ley No 27038, publicada el 31 de diciembre de 1998.

12. Artículo sustituido por el artículo $36^{\circ} \mathrm{de}$ la Ley No 27038, publicada el 31 de diciembre de 1998.

13. Párrafo sustituido por el artículo $13^{\circ}$ de la Ley No 27335, publicada el 31 de julio de 2000.

14. Artículo sustituido por el artículo $41^{\circ}$ de la Ley No 27038, publicada el 31 de diciembre de 1998.

15. Artículo sustituido por el artículo $42^{\circ}$ de la Ley No 27038, publicada el 31 de diciembre de 1998.

16. Artículo sustituido por el artículo $45^{\circ} \mathrm{de}$ la Ley No 27038, publicada el 31 de diciembre de 1998.

17. Artículo $158^{\circ}$ Artículo incorporado por el Artículo $77^{\circ}$ del Decreto Legislativo No. 953, publicado el 04 de febrero de 2004. 